\title{
Use of the Novel Synthesized Aqueous Binders for Pigment Printing Cotton Fabrics Using Three Modes of Fixation
}

\author{
K. Haggag ${ }^{1}$, M. M. El-Molla ${ }^{1, *}$, N. O. Shake ${ }^{2}$, N. A. Alian ${ }^{2}$, F. N. El-Shall ${ }^{1}$ \\ ${ }^{1}$ Textile Research Division, National Research Centre, Dokki, Cairo, Egypt \\ ${ }^{2}$ Faculty of Science (Girls), Al-Azhar University, El-Nasser City , Cairo, Egypt
}

\begin{abstract}
Use of the synthesized aqueous polyurethane acrylate (no volatile organic compound emission) binders 1-7, in pigment printing of cotton fabrics using silk screen technique. FT-IR spectra of binders via UV curing show the disappearance of ast $\mathrm{C}=\mathrm{C}$ and $\delta:=\mathrm{C}-\mathrm{H}$ absorption bands from the spectra chart of cured, which proofed the occurrence of cross linking reaction via terminal free acry late double bond. Color strength of printed fabrics depends on binders' type and concentration as well as the fixation temperature. The K/S values at lo wer fixation temperatures on using the prepared binders in the printing paste are better than the K/S of fabric printed with paste including the commercial binder at the same condition ( saving energy\& money). The fastness properties of the printed samples depend on the type of binder used. The washing and perspiration ranged from good to excellent for all printed samples. Slightly enhancement in K/S values of printed cotton fabric with increase the concentration of aliphatic polyurethane acrylate binders was noticed. The presence of $1 \%$ concentration of polyurethane acrylate binders (1-7) in the cotton pigment printing paste, and either UV curing or microwave cured for $3 \mathrm{~min}$. could be considered as optimum conditions. Improved rubbing fastness results for all the printed samples using the synthesized polyurethane acrylate binders in printed paste and UV cured are noticed as compared to those obtained by the traditional thermal curing technique. The results show that these binders can be used safely in preparing printing paste for printing cotton fabrics using pigment dyes.
\end{abstract}

Keywords Binders, Pigment Printing Cotton Fabrics, Thermal, UV, Microwave Fixation

\section{Introduction}

The difference between dyeing processes and pigmentati on is that pigment colored textiles require a curing procedure. Since pigments do not have an affinity to textiles. Pigment fixation on textiles relies on binders that require a curing process to hold the pigments on a textile. Conventional curing is a thermal process where pigment colored textiles must be dried and then cured with heat to convert the soft organic base (monomer and/or oligomers) to a tough polymer[1].

Currently, pigment print ing is perhaps the most commonly and extensively used technique for printing textiles, due to its obvious advantages[2,3], such as versatility; ease of near final print at the printing stage itself, applicable to almost every kind of fiber or mixture, and the ability to avoid any washing processes after fixation[4]. However pigment printing has a few problems -relatively high temperature cure, stiff hand and poor crock fastness of printed goods.

* Corresponding author:

melmolla@yahoo.com (M. M. El-Molla)

Published online at http://journal.sapub.org/textile

Copyright (C) 2012 Scientific \& Academic Publishing. All Rights Reserved
These disadvantages are related to binder used. Thus, to improve the quality of pig ment goods, the overall properties of the binders need to be improved. Methods to lower the curing temperature have received the most attention because the high temperature cure process not only wastes energy but also runs the risk of destroying substrates that can't endure high temperature processes.

Radiation curing technologies(as UV and microwave) are used in much industrial application as well as in the textile area[5], because of low energy consumption, short start-up period, fast and reliable curing, low environ mental pollution, fixation at room temperature, space saving, etc.

Microwave irradiation is a well-known method for heating and drying materials and is utilized in many private hous eholds and industrial applications. It offers a number of advantages over conventional heating, such as noncontact heating (circumventing the decomposition of molecules close to the walls of the reaction vessel), instantaneous and rapid heating (resulting in a uniform heating of the reaction liquor), and highly specific heating (with the material selectivity emerging from the wavelength of microwave irradiation that intrinsically excites dipolar oscillation and induces ionic conduction)[6]. The aim of this work is aimed to investigate the use of the aqueous polyurethane acrylate, 
synthesized in part 1 as binders which having zero volatile organic emissions (aqueous binders) based on polyethylene glycol with different molecular weight and Polyol mixture, in pigment printing of cotton fabrics using silk screen technique, and pigment fixation through the polymerization process of the binder by using the thermo fixation mode, and the newly adopted UV and mic rowave techniques.

\section{Experimental}

\subsection{Materials}

$100 \%$ scoured bleached cotton fabric of $140 \mathrm{~g} / \mathrm{m}^{2}$ was supplied by Miser El -Mehalla Kubra, Co. for Spinning and Weaving, Egypt.

Bercolin Red B3E pigment. Supplied by Berssa Co., Turkey.

Ammonium per sulfate (NH4)2S2O8 Merck, Germany as a thermal initiator.

Esacure DP 250 supplied by Lamberti Spa Italy as Photo -initiator.

Bercolin CPK, supplied by Berssa, Turkey as thickening agents.

Binders: The different aqueous polyurethane acrylate synthesized[7] based on polyethylene glycol with different molecular weight and polyol mixture were used as binders. The first four binders based on isophoron diisocyanate were: Binder1 PUA based on PEG 6000g/mol+ Polyol +HEA

Binder2 PUA based on PEG $12000 \mathrm{~g} / \mathrm{mol}+$ Polyol + HEA, Binder3 PUA based on PEG $20000 \mathrm{~g} / \mathrm{mol}+$ Polyol +HEA, Binder4 PUA based on PEG $20000 \mathrm{~g} / \mathrm{mol}+$ Polyol +HPMA.

The last three binders based on toluene diisocyanate.

Binder5 PUA based on PEG $20000 \mathrm{~g} / \mathrm{mol}+$ Polyol + HEA, Binder6 PUA based on PEG $20000 \mathrm{~g} / \mathrm{mol}+$ Polyol +HPMA. Binder 7 PUA based on PEG $6000 \mathrm{~g} / \mathrm{mol}+$ Polyol + HPMA

Two different co mmercial binders were used:

Bercolin metal CM supplied by Berssa, Turkey as thermal curing binder.

Ebecryl 2001 supplied by Surface Specialties UCb, Belgium, as radiation curing binder.

\subsection{Methods}

\subsubsection{Curing of Prepared Binders Using UV Rays}

Prepared binders of $0.1 \mathrm{~g}$ were well mixed with $0.1 \%$ Esacure DP 250, photo in itiator and subjected to UV rays at wave length $254 \mathrm{~nm}$. The resulting cross linking films was investigated by FTIR spectroscopy.

\subsubsection{Preparation of Printing Pastes}

The pigment printing pastes were prepared according to the following recipe:

\begin{tabular}{cc} 
Pigment & $50 \mathrm{~g}$ \\
Binder* & $\mathrm{X}$ \\
Thickener & $40 \mathrm{~g}$ \\
Initiator** & $10 \mathrm{~g}$ \\
Distilled water & $\mathrm{Y}$ \\
\cline { 2 - 2 } & $1000 \mathrm{~g}$ \\
concentrations were (1, 2, 3, and4\%) &
\end{tabular}

**The initiators were either thermal initiator (ammonium per sulfate) or photo initiator (Esacure DP250)

\subsubsection{Printing Techniques}

Two printing pastes containing, the thermal initiator or UV curing photo initiator, in addition to the other ingredients were prepared. The homogenized printing pastes were applied to the fabrics using a flat screen technique.

\subsubsection{Pig ment Fixation}

The samples printed with the thermal paste (i.e. including the thermal initiator). were thermo fixed at different temperatures $\left(80,100,120\right.$ and $\left.160^{\circ} \mathrm{C}\right)$ for period of $4 \mathrm{~min}$, while the samples printed with the pastes including the photo initiator, were either fixed using UV rays at wave length 254 $\mathrm{nm}$, for (3,5, and $10 \mathrm{~min}$.), or using micro wave oven at 500 watt for $(3,4,5 \mathrm{~min})$.

\subsection{Measurements and Analysis}

\subsubsection{Color Strength Measurements}

The relative colour strength of the prints, expressed as K/S value[8] of the coloured samples, was determined by reflection measurements using data colour international model SF 500, USA.

\subsubsection{Fastness Properties}

Fastness to washing[9], rubbing[10] and perspiration[11] was assessed according to the standard methods.

\section{Results and Discussion}

The aim of this paper is to investigate the possibility of using the prepared polyurethane acrylate poly mers based on PEG with different molecular weight and polyol mixture (part 1) as binders for pigment printing of cotton fabrics, using silk screen techniques. The results were always compared with those obtained when a commercial binder was used in every case under similar conditions. Fixations of the prints were achieved via thermo fixation (conventional method) as well as via UV and micro wave techniques. 


$$
\begin{aligned}
& \mathrm{S}_{2} \mathrm{O}_{8}^{--} \longrightarrow \mathrm{2O}_{4}^{-} \\
& \mathrm{SO}_{4}^{-}+\mathrm{H}_{2} \mathrm{O} \longrightarrow \mathrm{H}^{+}+\mathrm{SO}_{4}^{-}+\mathrm{HO} \\
& 2 \mathrm{HO} \longrightarrow \mathrm{H}_{2} \mathrm{H}_{2} \longrightarrow \mathrm{H}_{2} \mathrm{O}_{2} \\
& \mathrm{H}_{2} \mathrm{O}_{2}+\mathrm{OH} \longrightarrow \mathrm{H}_{2} \mathrm{O}+\mathrm{HO}_{2}^{-} \\
& \mathrm{HO}_{2}^{+}+\mathrm{S}_{2} \mathrm{O}_{2}^{-} \longrightarrow \mathrm{O}_{2}+\mathrm{HSO}_{4}^{-}+\mathrm{SO}_{4}^{-}
\end{aligned}
$$

Scheme 1. Mechanism of radical generation via thermal initiation

In thermo fixation technique the corsslinking reaction was initiated by thermal decomposition of the persulphate groups to produce sulphate ion radicals alone with their radical species. The radical formed in this way were used as initiators for the cross linking reaction. The mechanism of free radical generation reaction is shown by following scheme $1[12]$.

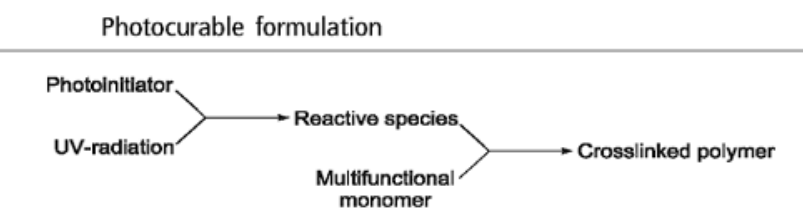

Scheme 2. Formulation of photocurabel system

Thus, the acrylate terminal double bond polymerization can be initiated by either the $\mathrm{SO}^{-\cdot}$ or by ${ }^{\circ} \mathrm{OH}$ radicals. In the presence of polyurethane acrylate, these free radicals can attack polyurethane at terminal ends (double bond), thereby give rise to form macro radicals capable of initiation the crosslinking reaction (crosslinking polymerization of the polyurethane). Radiation curing is an alternative to the thermal process. Radiation curing resin formulations contain monomers, and photo initiators. These components can be polymerized (hardened) by the free radical mechanis $m$ as shown in scheme 2[13].

The free radical generated by mean of high energy radiation[14-16] is shown in the following scheme 3. Use of a photo initiator triggers a nearly instantaneous curing reaction upon exposure to UV light.

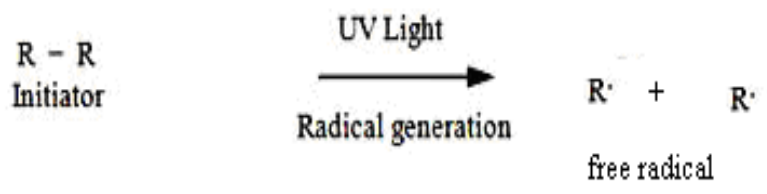

Scheme 3. Generation of free radical via photoinatiation

Thus UV curing produces a completely polymerized network in seconds which is faster than thermal curing[17]. After free radical has been generated the polymerization reaction was occurred as following:

The curing process creates a tightly crosslinked poly mer network[13], which is represented schematically in Scheme 5, The mentioned mechanisms and chemical change occurring upon UV exposure of prepared PUA (i.e., the disappearance of reactive groups) can be monitored by using FTIR spectra.<smiles>[R]C=C[R]</smiles>

\section{Initiation}<smiles>[R]C=CC([R])[CH]</smiles><smiles>[R]CC([R])CC([R])C[R]</smiles><smiles>[R]CC([R])[CH+]</smiles><smiles>[R]CC([R])[R]</smiles>

Scheme 4. Mechanism of radical polymerization

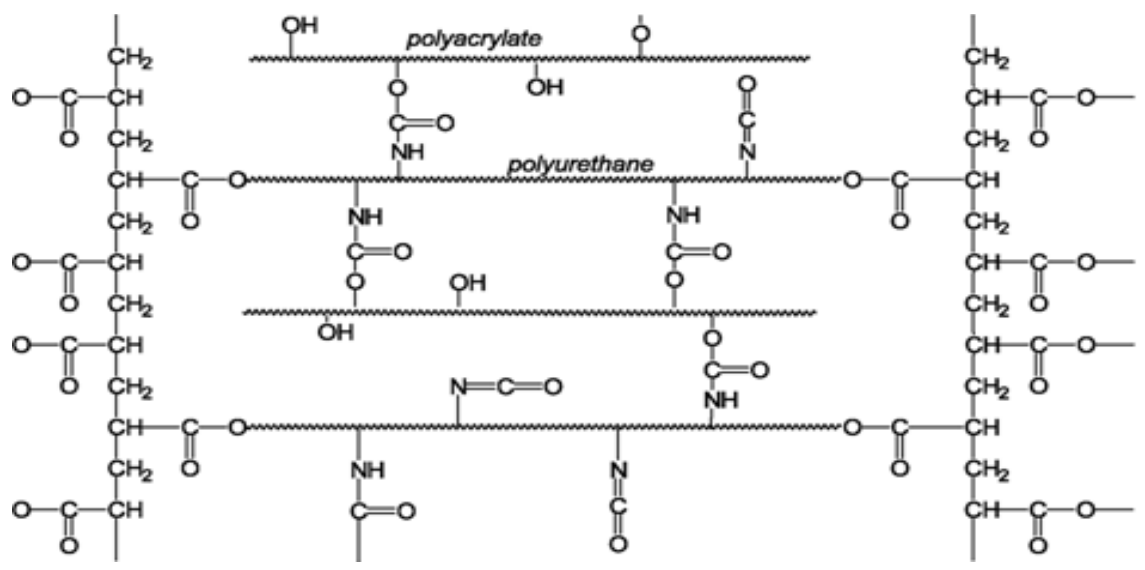

Scheme 5. Grosslinked polymer net work 
Figures (1-7) for cured PUA polymers, shows the disappearance of ast $\mathrm{C}=\mathrm{C}$ and $\delta:=\mathrm{C}-\mathrm{H}$ absorption bands at almost $1986 \mathrm{~cm}^{-1}$ and $958 \mathrm{~cm}^{-1}$ respectively. From the spectra chart of cured, which proofed the occurrence of crosslinking reaction via terminal free acrylate double bond, it is clear from the previous results that the prepared PUA could be used as self crosslinking binders in pigment printing.

One of the distinct advantages of waterborne UV- cured PUA is that they combine hardness and flexibility[18].

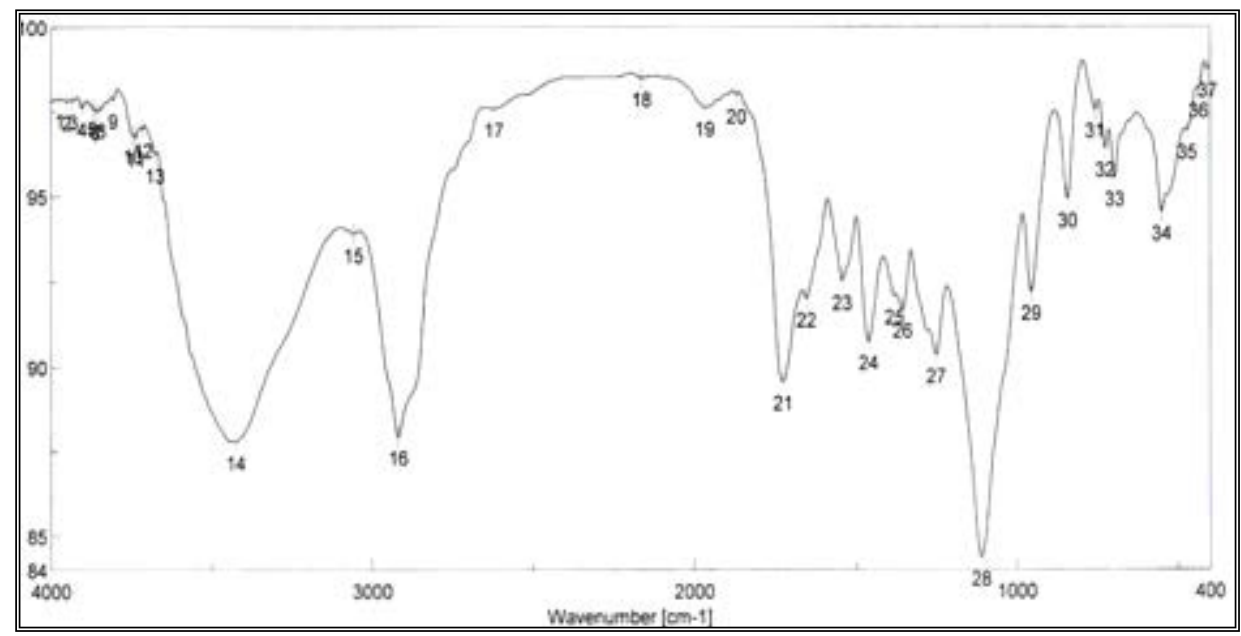

Figure 1. FTIR spectra of binder 1 after UV curing

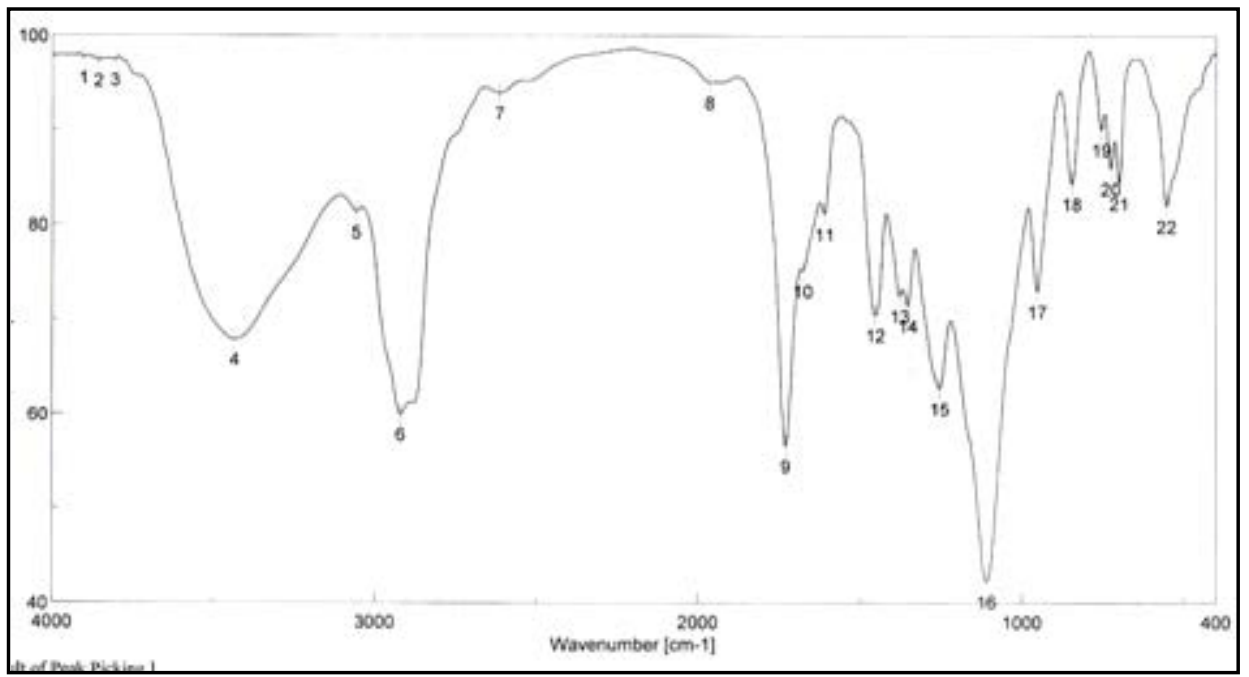

Figure 2. FTIR spectra of binder 2 after UV curing

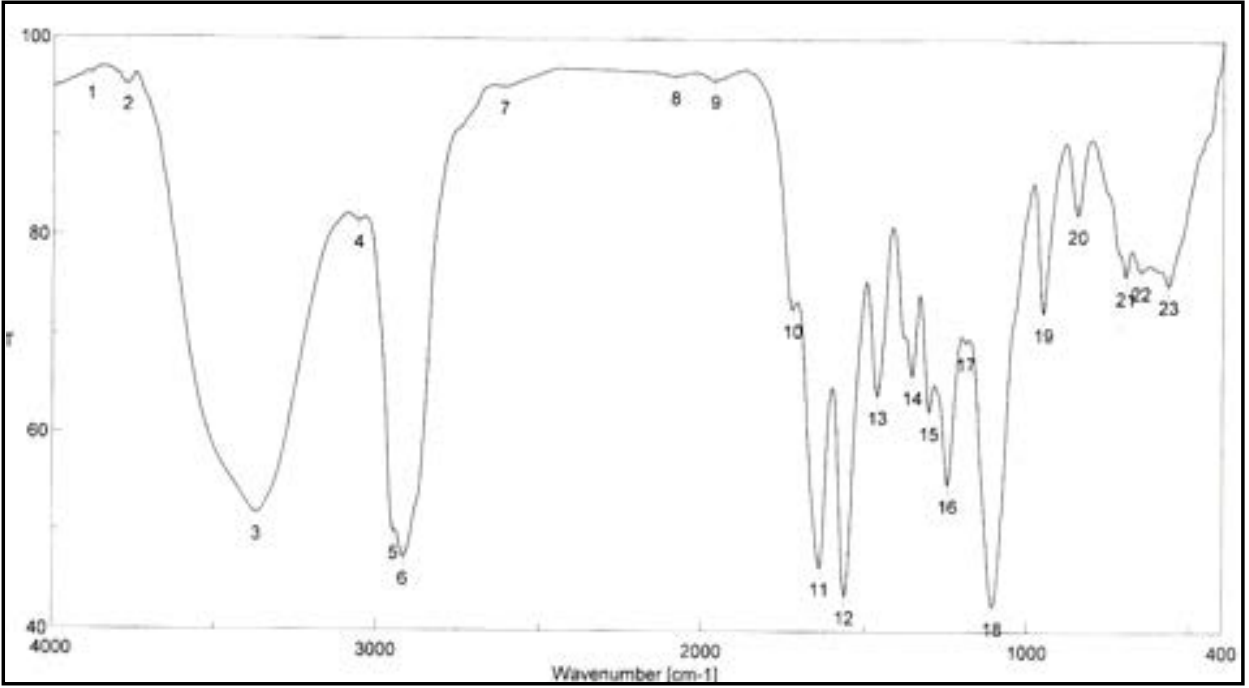

Figure 3. FTIR spectra of binder 3 after UV curing 


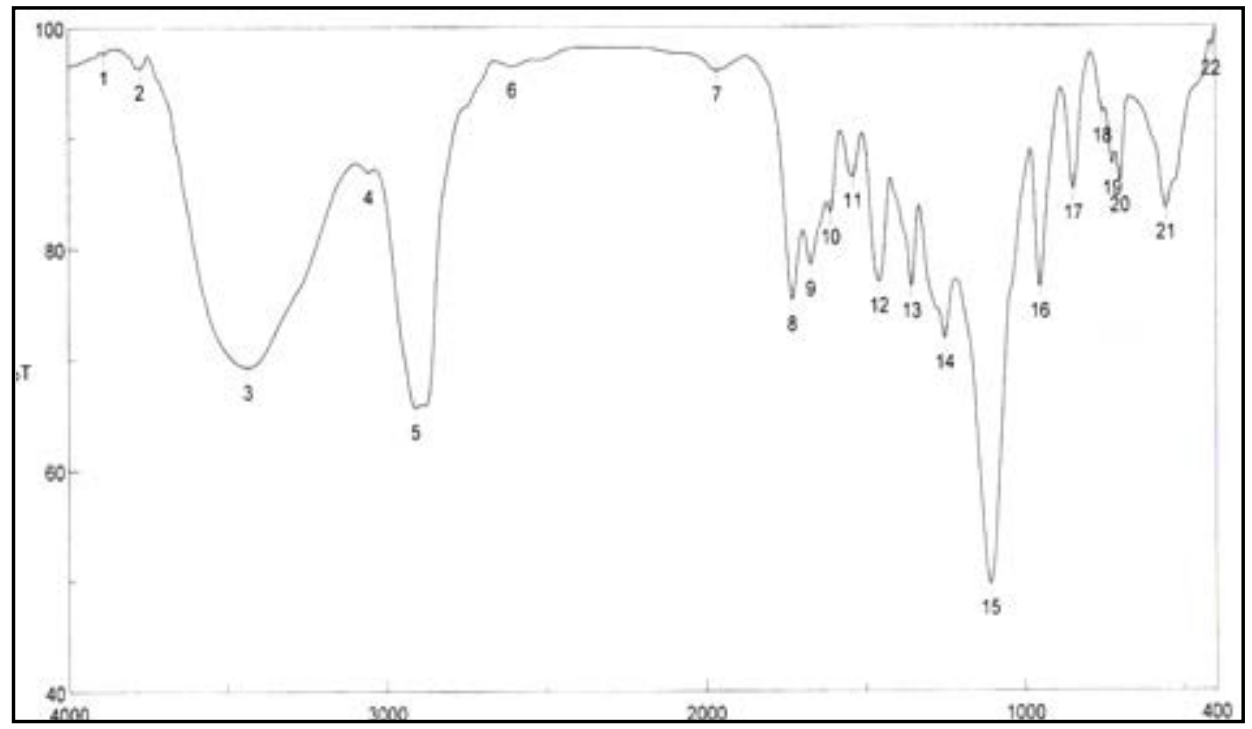

Figure 4. FTIR spectra of binder 4 after UV curing

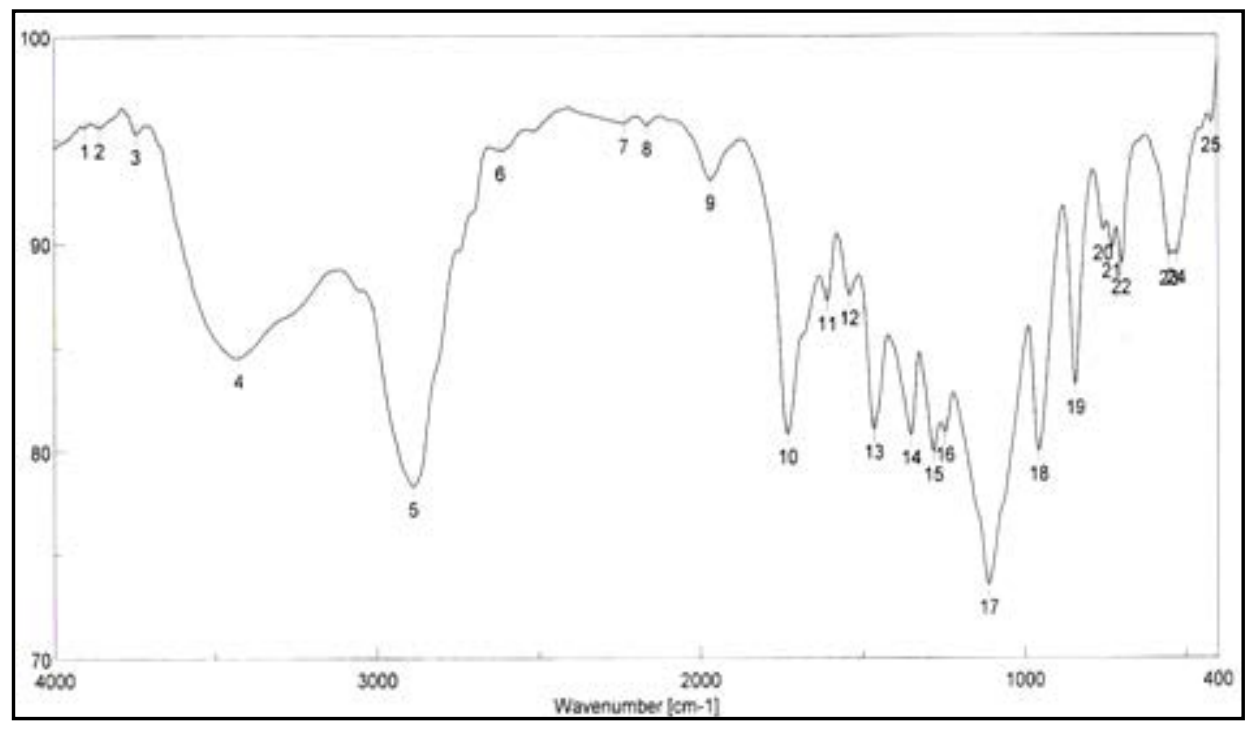

Figure 5. FTIR spectra of binder 5 after UV curing

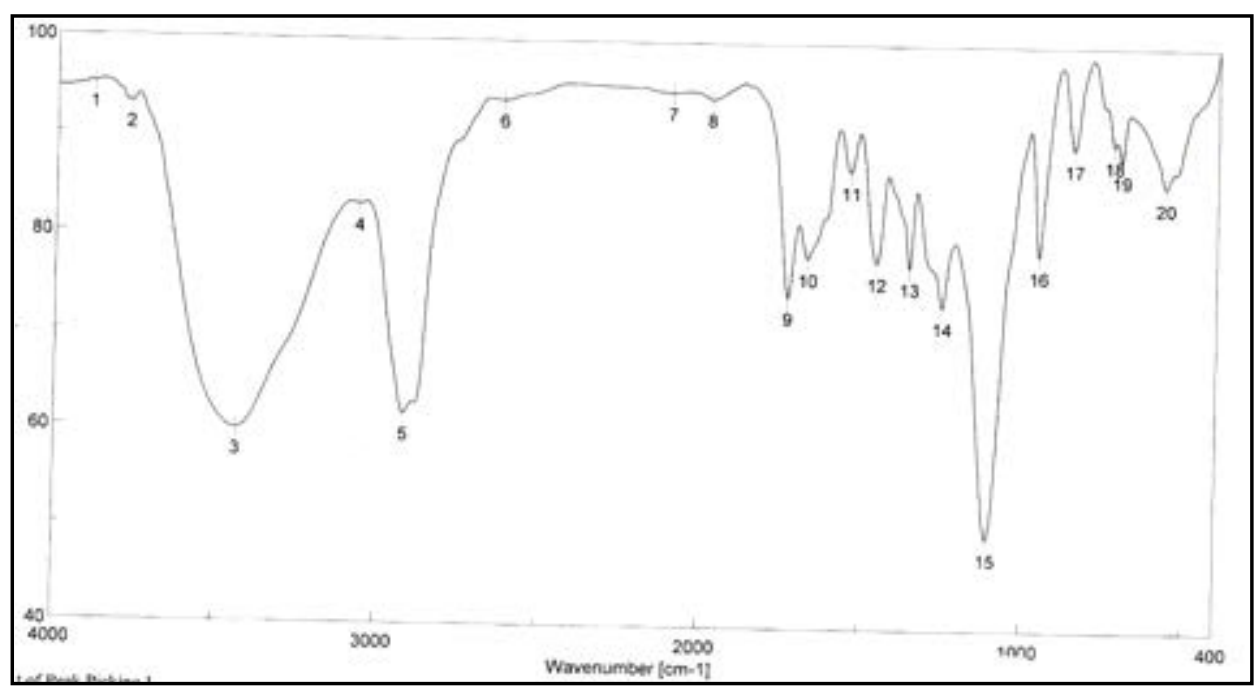

Figure 6. FTIR spectra of binder 6 after UV curing 


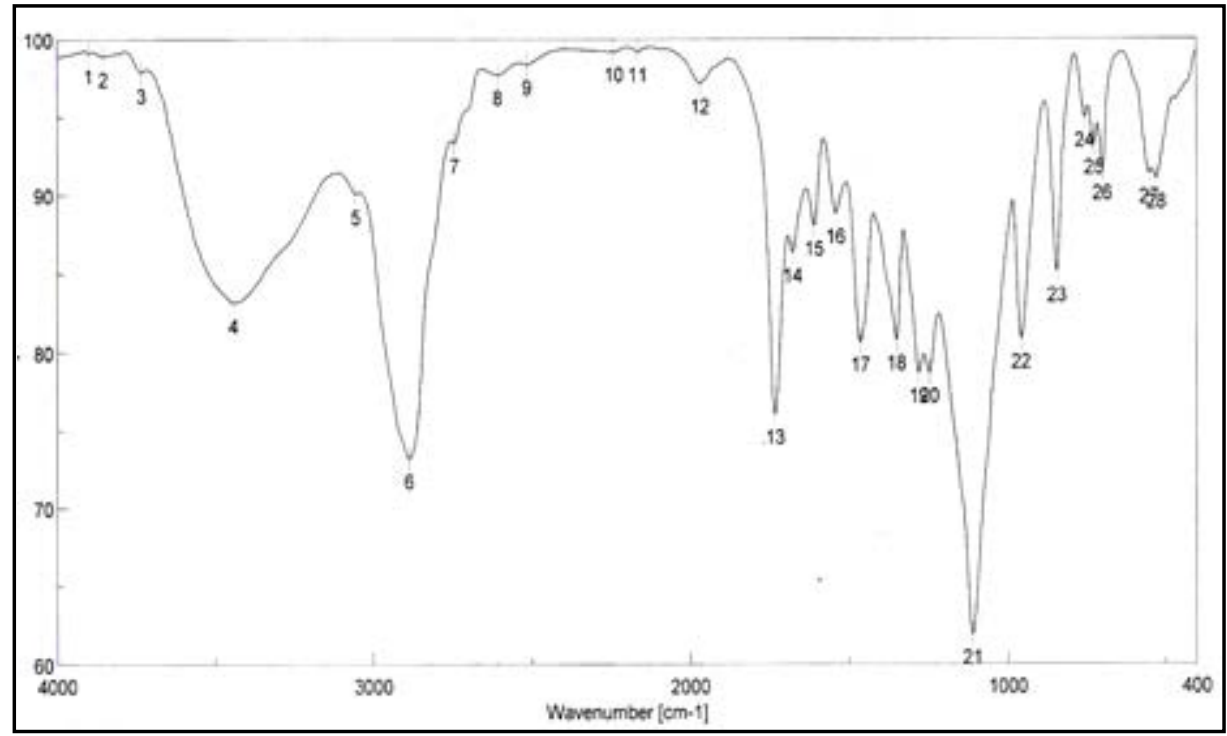

Figure 7. FTIR spectra of binder 7 after UV curing

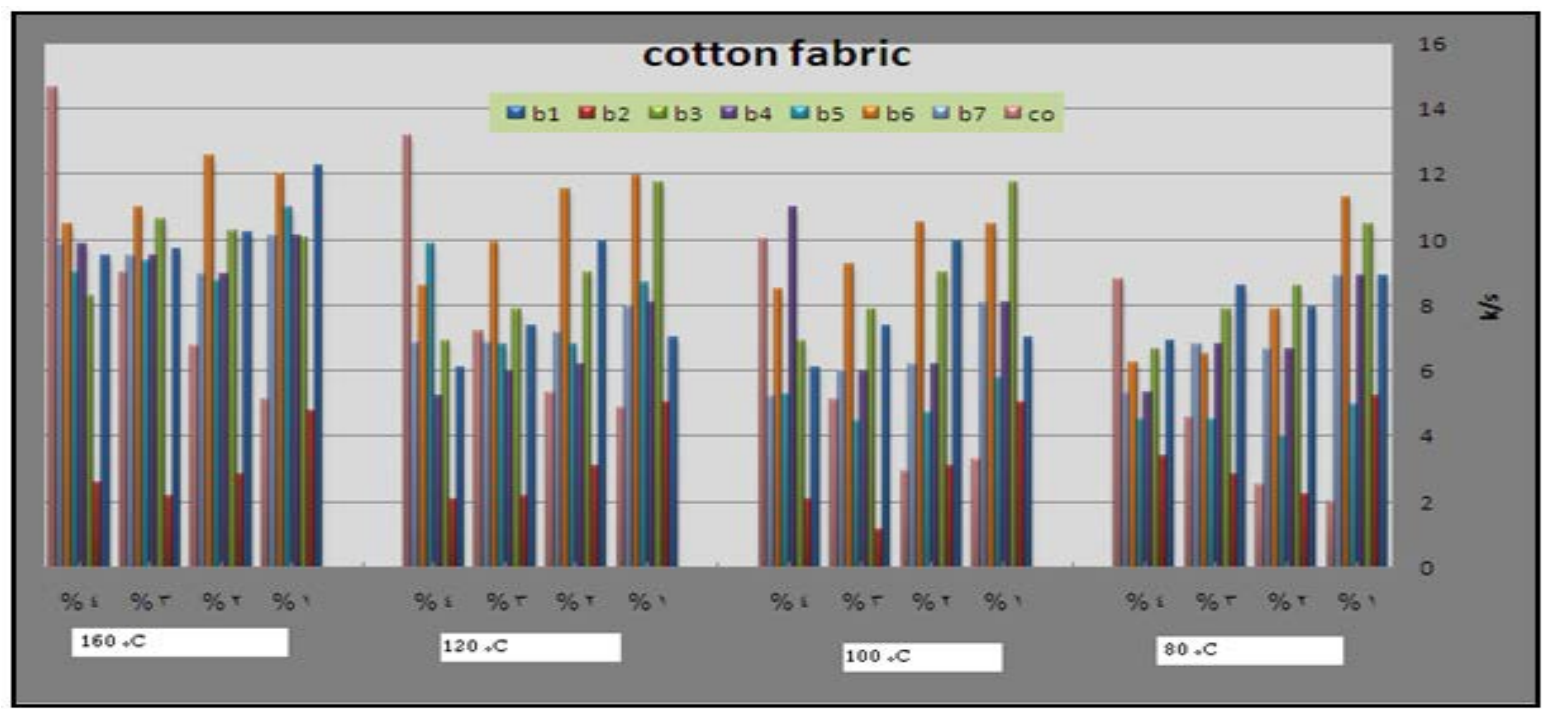

Figure 8. Effect of thermo fixation temperat ure, type of binders(1-7) as well as commercial binder and their concentrat ion on the color strengh of pigment printed cotton fabric

\subsection{Effect of Fixation Temperature, Type of Binders and Their Concentration on the Col or Strength of Printed Samples}

In the first stage of the investigation, the prepared pigment pastes, containing 5\% Bercolin Red B3E, and different concentrations (1, 2, 3, and $4 \%$ ) of the synthesized polyurethane acrylate (binders 1-7), as well as the commercial binder (thermal type), were printed on cotton fabrics by the flat silk screen technique, dried then thermally polymerized with hot air at different fixation temperatures $\left(80,100,120\right.$ and $\left.160^{\circ} \mathrm{C}\right)$ for $4 \mathrm{~min}$. The color strength results of the pigment printed cotton fabrics are represented by Figure 8.

The collective diagrams show the effect of the aforementioned binders on the color strength of the printed cotton fabrics thermally cured under the above conditions. It is clear from the results that the color strength of printed cotton fabric depends on binders' type and concentration as well as the fixat ion temperature. It can be seen that for almost type of binders color strength of printed cotton fabric is higher at low concentration and this is true irrespective of the fixation temperature. This may be due to the probability of self polymerization at higher concentration. It is also clear that K/S of the fabric printed using pastes including the synthesized binders are higher than the color strength of fabric printed with pastes including the commercial binder, this hold is true at only low temperatures.

From figure 8 it is clear that, the synthesized binders give acceptable results for color strength values at low fixation temperature. This may be attributed to the presence of functional groups (double bond, hydroxyl groups) which are able to increase the crosslinking density.

We can conclude that binders 1,3 and 6 have the best results for color strength at low fixation temperature and low binder concentration. 


\subsection{Effect of UV Fixation Time, Type of Binders and Their Concentration on Col or Strength of Printed Samples}

Pigment printing cured via irradiation (UV, microwave) eliminates the drying step and greatly reduces the energy required for curing. High curing speed, high cross-linking densities and the absence of organic solvents have made radiation curing a well established technology for all kinds of coating and ink applications[19].

Today numerous UV-curable monomers and like polyether, polyester, epoxy, polyacrylate and urethane acrylates are available on the market. By the choice of raw materials, namely as binders and accompanying monomers, and photo initiators, the film properties such as hardness, flexibility, resistance and adhesion can be controlled in a very flexible way[20-22]. Acrylic monomers do not absorb UV-light in a very efficient way and will not in itiate radical polymerization fast enough. As such, a photo polymerisable film forming formulation essentially consists of a polymerisable vehicle and a light sensitive compound that is able to convert the absorbed light energy into a more useful form capable of causing the binder to polymerize into a hard solid mass.

Such a light sensitive compound is known as photo initiator/ sensitizer. Thus a photo initiator is added to produce initiator free radicals directly by the fragmentation of the photo-excited state; these free radicals are capable of initiating the polymerization reaction[23].

Photo initiator is of paramount importance in radiation curable systems. A photo initiator is selective in terms of light of specific wavelengths. During formulation, the absorbency characteristics of the photo initiator are matched to the radiation characteristics of the lamp output. Indeed, the choice of photo initiator is of prime impotence in the light induced polymerization since it directly governs the cure rate[24].

As mentioned before, the prepared pigment pastes containing Bercolin Red B3E pigment, and different concentrations $(1,4 \%)$ of the prepared polyurethane acrylate (binders 1-7), as well as the selected suitable UV curing commercial binder Ebecryl 2001 and the photo initiator Esacure DP 250 were printed on cotton fabrics by the flat screen technique, dried and then subjected to UV curing for different intervals of time 3,5 , and 10 minutes.

The results are expressed in Figure 9. Binders (1-7) with different structures containing some unsaturated groups, which under the effect of UV rays can undergo a polymerization reaction which leads ultimately to pigment fixation on the cotton fabrics. As regarding to the binder concentration, slightly enhancement in K/S values of printed cotton fabric with increasing the concentration of binders $1,2,3,4$ (aliphatic polyurethane acrylate) this may be attributed to the increase of the unsaturated double bonds, so when they are subjected to UV curing results in higher degree of polymerization crosslinking.
The highest K/S value is obtained on using binder4 at high concentration this may be due to percents HPMA. The ability of HPMA to expand the backbone increases corsslinking ability of that binder.

Also it can be seen that, binder concentration of $1 \%$ produces cotton printed samples with color strength values higher than those obtained by binder concentration of $4 \%$ under similar fixation conditions in case of binders 5, 6 and 7 . This may be due to the presence of benzene rings along the structures (aromatic urethane acrylate) the aromatic ring dissipates radiation energy due to the high conjugation double bond system[25].

Binder 6 shows highest $\mathrm{K} / \mathrm{S}$ values at lower binder concentration that may be due to its structure (based on PEG 20000 and HPMA) which elongates its backbone. With regards to the type of binder used it can be noticed that, in general, the highest color strength values were obtained in case of using binder 4 and 6in the UV curable printing pastes while lowerva lues were obtained upon using the commercial binder (Ebecryl 2001) and moderate values, in case of using binders 1, 2, 3, 5 and 7. This is true irrespective of either the binder concentration or the UV-curing time. This could be attributed to the difference in structure of the binders used as well as the difference in their contents of the unsaturated groups, which are responsible for the pigment fixation, and also to the influence of UV rays on these different structures.

It is also clear from Figure 9 that, increasing the UV-curing fixation time from 3 to 5 and up to $10 \mathrm{~min}$. did not result in any significance increase in the color strength values of the cotton printed samples irrespective of the type and concentration of the binders used in these experiments. This may be due to the rapid curing process, on using UV rays on fixation process. A curing time of $3 \mathrm{~min}$. could be recommended under such circumstances to save energy and time.

Generally it could be concluded that, the presence of $1 \%$ concentration of polyurethane acrylate binders (1-7) in the cotton pigment printing paste, and UV curing for $3 \mathrm{~min}$. could be considered as optimum conditions.

\subsection{Effect of Microwave Fixation Time, Type of Binders and Their Concentration on the Color Strength of Printed Samples}

Microwave irradiation is one of powerful techniques of noncontact heating, because the dielectric substances with large dielectric loss constant vigorously fever by vibration and rotation of permanent dipole in microwave field. Microwave has been used for reacting, drying, curing, fin ishing of cellu losic-based textile[26]. Mic rowave heating has been proved more rabid, uniform, and efficient. It penetrated easily into particles, which can be heated simultaneously, thus reduction heat transfer problems. So me studies have been investigated the possibility of using micro wave heating in dyeing and printing of different fabrics as well as the effect of microwave irradiation on their fabric structure[26]. 
The prepared pigment pastes containing Bercolin Red B3E pigment, and different concentrations (1, and 4\%) of the prepared polyurethane acrylate binders (1-7), as well as the selected suitable commercial binder Ebecryl 2001 and the photoinitiator Esacure DP 250 were printed on cotton fabrics by the flat screen technique, then introduced into microwave oven as it is wet without drying, to be cured for different interval of times (2, 3, $4 \mathrm{~min})$ at operating power at 500 watt. The results are shown in Figure 10. Regarding the type of binder derivatives, it can be noticed that it has no significant influence on the color strength values of the printed fabric at low binder concentration irrespective of the fixation time. While at higher concentration there is some difference in color strength of some binder derivatives, this may be attributed to the role of electromagnetic waves and their influence on different binder derivatives (difference in their structure, their content of unsaturated groups, and difference in backbone). Color strength values observed for cotton fabric printed using pastes including the prepared binders are higher than those obtained using the commercial one; this hold is true irrespective of fixation time and binder concentration, due to the nature of microwave dielectric heating[27] and the use of unmodified domestic house hold oven accurate temperature measurement using conventional means of temperature determination during the irradiation process were not possible.

Therefore the reason for the observed rate-enhancement were in many cases not fully understood and led a lot of speculation and fierce debate of existing of so-called non-thermal or specific micro wave effect.
The results in the collective diagram 10 show that, the concentration of the prepared binders of polyurethane acrylate binder derivatives (1-7) in the printing paste has slightly effect on the color strength values of the screen printed cotton fabrics. So on using lower concentration of these binders $1 \%$ and subsequently microwave cured for different interval of times (2, 3, and $4 \mathrm{~min}$ ), K/S values are more or less comparable with those printed using higher concentration of these binders $4 \%$ under the same conditions. This may be due to the self polymerization of high binder concentration when the prints are exposure to microwave irradiation.

It is also clear from Figure10 that, increasing the micro wave curing fixation time from 2 and up to 4 min gives results with slightly increase in the color strength values of the cotton printed samples irrespective of the type and concentration of the binders used. This may be attributed to the fast drying of prints during their espousing to mic rowave irradiation. Material including water, are described as loss and may be heated by the use of microwaves, hence due to the fact that the molecular chains in their structure have resonant frequencies similar to the frequency of microwave energy, so that strong interaction occurs, the molecules vibrating violently and causing heat to be generated[28] .

It could be concluded that the presence of $1 \%$ concentration of polyurethane acrylate binders (1-7) in the cotton pigment printing paste, and microwave curried for 3 min. could be considered as optimum conditions.

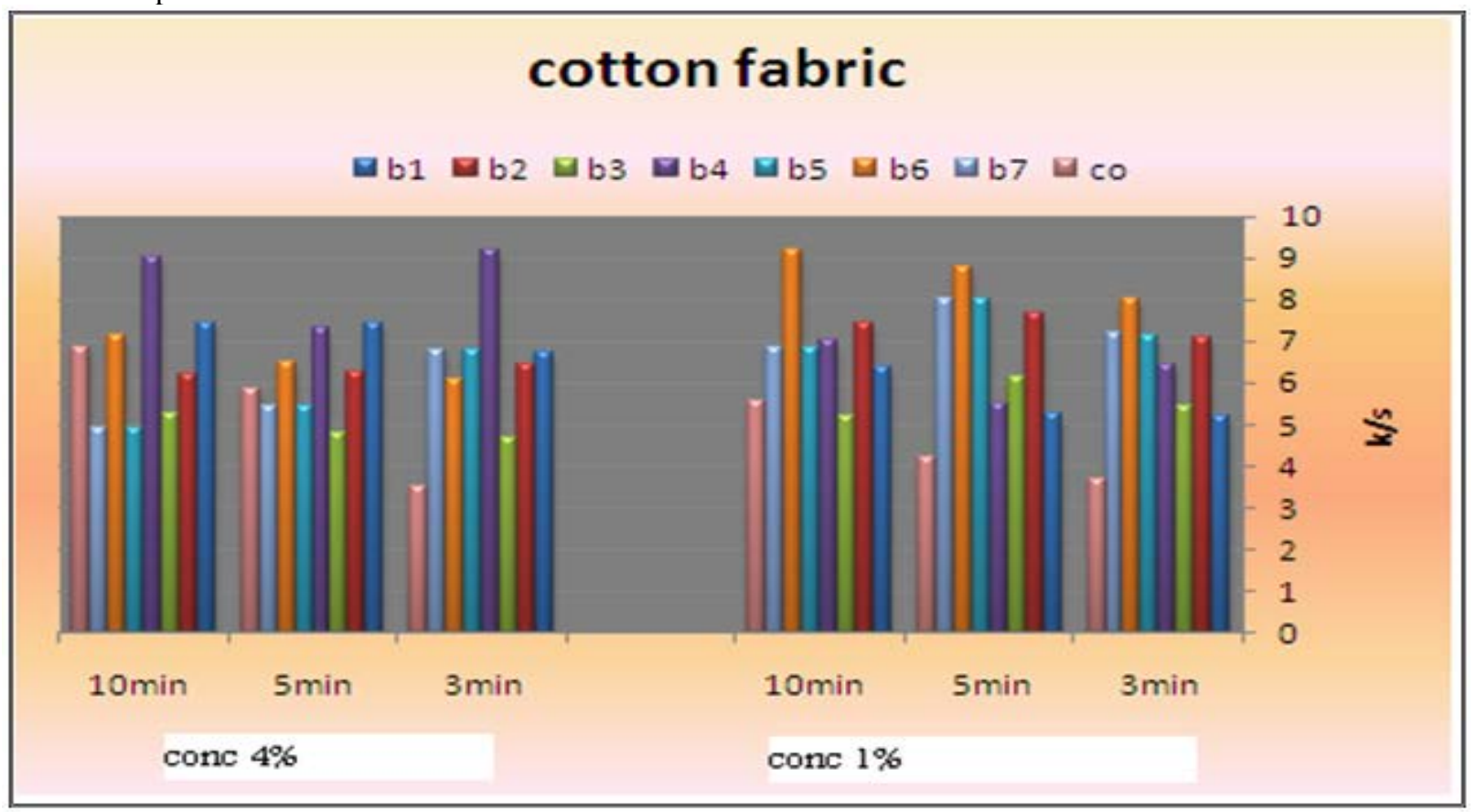

Figure 9. Effect of fixation time and binder (1-7and commercial)types and their concent ration on the color strength of pigment printed cott on fabrics using UV irradiation technique 


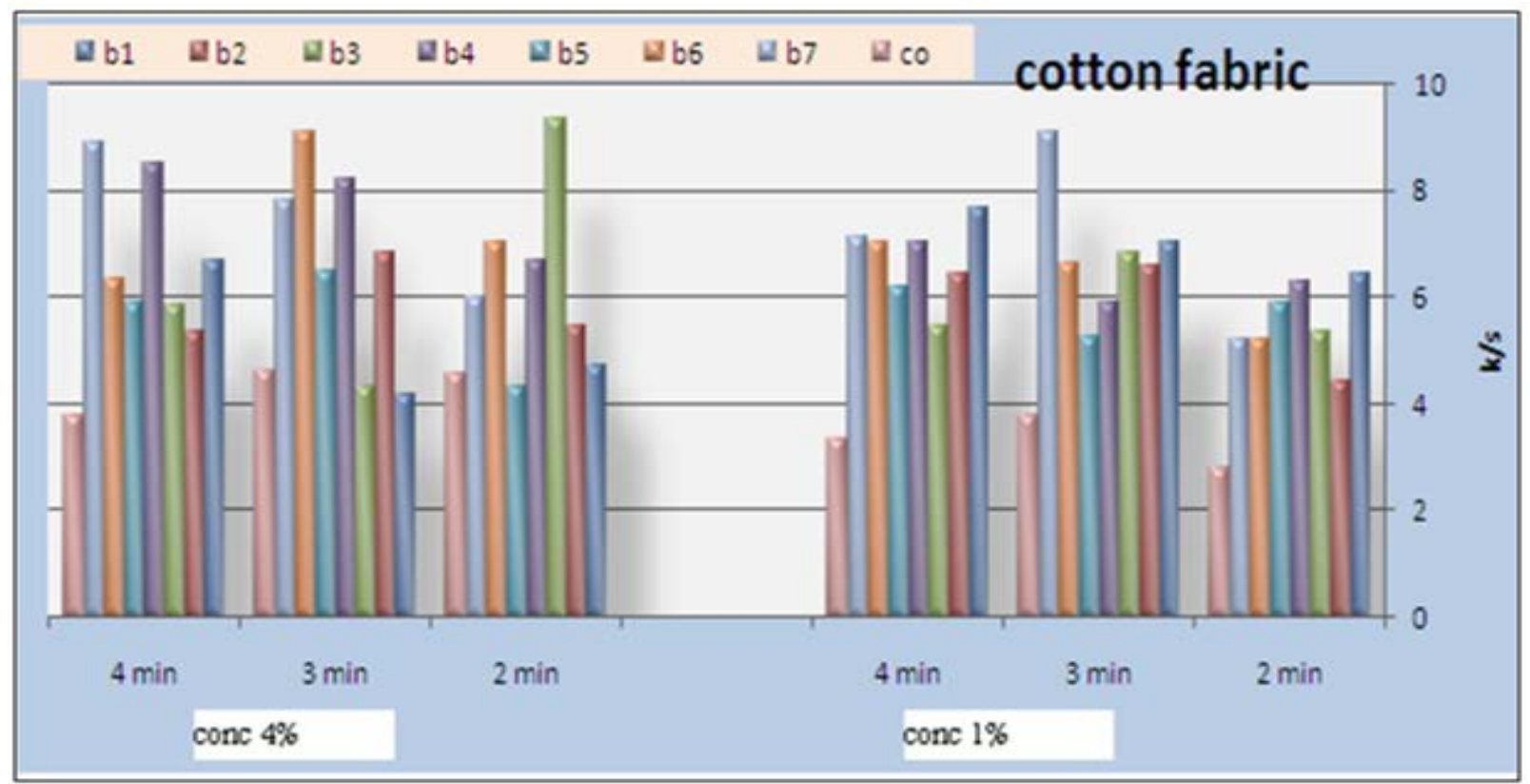

Figure 10. Effect of fixation time and binder types (1-7 and commercial one) and their concentration on the color strength of pigment printed cotton fabrics using microwave irradiation technique Where $* \mathrm{~b}=$ synthesized binder , co $=$ commercial binder

\subsection{Effect of the Mode of Fixation on the Color Strength of the Printed Samples}

The color strength results obtained by thermal, UV and microwave fixation techniques for screen printed cotton fabrics with pigment past containing $4 \%$ Bercolin red B3E pigment and $1 \%$ binder concentration (binder 1-7) and to those obtained by commercial binders are represented by Figure11.

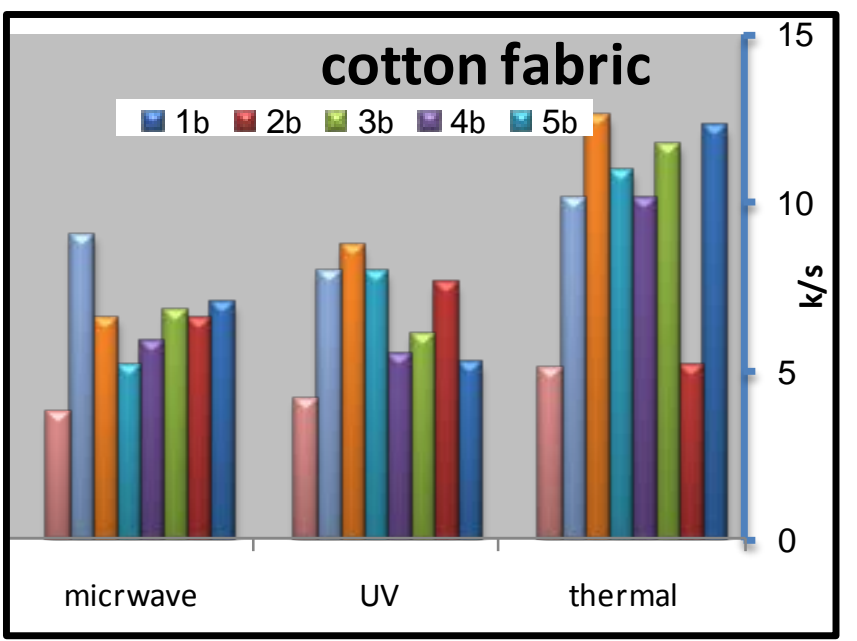

Figure 11. Effect of the mode of fixation on the color strength of the printed cotton samples

- Thermo fixation temperature $160^{\circ} \mathrm{C}$ for $4 \mathrm{~min}$

- UV curing time $5 \mathrm{~min} *$ Mic rowave curing time 3

The results show that, under the selected thermal fixation conditions of $160^{\circ} \mathrm{C} 4 \mathrm{~min}$, UV curing conditions of $5 \mathrm{~min}$ and microwave curing of $3 \mathrm{~min}$, the thermo fixed printed samples possessed higher color strength values when compared with the corresponding UV and micro wave cured printed samples upon using synthesized binders, while the two latecomers are characterized by better fastness properties.

The highest K/S is obtained with binder 1, 6 in case of thermo fixed printed cotton samples. It clear that the K/S of printed samples with pastes containing the synthesized binders and cured by using UV and microwave techniques are higher than the printed samples using commercial binder in its pasts and fixed by same mentioned techniques.

Generally spoken, the highest K/S values observed within radiation curing (UV and microwave) in case of binder 6, 7.

\subsection{Fastness Properties}

Since pigment printing using thermal, UV curing and microwaves curing is a surface application, the major concern is the abrasion resistance of the printed fabrics either towards washing or rubbing. In thermal curing process, the cross linking is essential for the adhesion of the binder to the textile surface and to give the pigment prints optimum fastness properties[29]. Apply ing high curing temperature to fix the pigment colors, as much as needed is an unfavorable printing aspect. It does not only waste energy but also runs the risk of the thermo degradation of substrates. In UV curing, these risks are minimized[30].

Tables 1 show the color strength and overall fastness properties of screen printed and thermally cured (at $160^{\circ} \mathrm{C}$ for 3min. ) cotton fabrics with pigment printing pastes containing $1 \%$ polyurethane acrylate binders (1-7), as well as $5 \%$ Bercolin Red B3E pigment, and of those obtained upon using the commercial binder (Bercolin metal CM) respectively. The results show that, both the color strength and the fastness properties of the printed samples depend on the type of binder used. Prepared binders gave printed samples with much higher color strength results as compared 
to those obtained upon using commercial binder at the same conditions. The rubbing fastness results were acceptable for thermally cured cotton printed samples, but improvement is noticed with binders 1, 2, 4, 5 and 6 as compared to those for binder 3, 7 and the commercial binder. The rubbing fastness ranging fro $m$ good to very good in case of using the binders 1 , 2, 4, 5, 6 and commercial binder and ranging from moderate to good in case of using binder3, 7. Moreover, washing and perspiration fastness properties were in the range of very good to excellent for fabric printed using the prepared binders in the printed pastes.
Table 2 shows the roughness properties of screen printed cotton using printing pastes containing $4 \%$ Bercolin Red B3E, $1 \%$ of the synthesized polyurethane acrylate binders(1-7), as well as the commercial binder Bercolin metal $\mathrm{CM}$ and thermally cured at $160^{\circ} \mathrm{C}$ for $4 \mathrm{~min}$. The results show that the roughness for both printed fabrics depends on the type of binder used. The commercial binder gave high roughness results to those obtained by synthesized binders.

Table 1. Overall fastness properties of pigment printed thermally fixed cotton fabric using prepared and commercial binders

\begin{tabular}{|cccccccccc|}
\hline Binder used & \multicolumn{4}{c}{ Rubbing } & \multicolumn{2}{c}{$\begin{array}{c}\text { Washing } \\
\text { fastness }\end{array}$} \\
& K/S & Dry & Wet & St. & Alt. & St. & Acidic Alt. & Alkaline \\
& & & & & & & & & At. \\
Commercial binder & 5.4 & 3 & 3 & $4-5$ & 4 & $4-5$ & 4 & $4-5$ & 4 \\
Binder 1 & 12.3 & $3-4$ & $3-4$ & $4-5$ & 4 & $4-5$ & 4 & $4-5$ & 4 \\
Binder 2 & 5 & $3-4$ & $3-4$ & 4 & 4 & 4 & 4 & 4 & 4 \\
Binder 3 & 10.2 & 3 & $2-3$ & $4-5$ & 4 & $4-5$ & 4 & $4-5$ & 4 \\
Binder 4 & 10.3 & $3-4$ & 4 & $4-5$ & 4 & $4-5$ & 4 & $4-5$ & 4 \\
Binder 5 & 11 & 4 & 3 & $4-5$ & 4 & $4-5$ & 4 & $4-5$ & 4 \\
Binder 6 & 12.2 & 4 & $3-4$ & $4-5$ & 4 & $4-5$ & 4 & $4-5$ & 4 \\
Binder 7 & 10.2 & $2-3$ & $2-3$ & $4-5$ & 4 & $4-5$ & 4 & $4-5$ & 4 \\
\hline
\end{tabular}

St. = Staining

Alt. $=$ Alteration

Table 2. Roughness properties of screen printed thermally fixed cotton fabrics using prepared and commercial binders

\begin{tabular}{|cc|}
\hline Binder used & Printed Cotton \\
Commercial & 16.3 \\
Binder & 10.8 \\
Binder 1 & 11.8 \\
Binder 2 & 15.7 \\
Binder 3 & 10.5 \\
Binder 4 & 12.02 \\
Binder 5 & 14.04 \\
Binder 6 & 10.11 \\
Binder 7
\end{tabular}

Table 3. Overall fastness propert ies of pigment printed UV cured cotton fabric using prepared and commercial binders

\begin{tabular}{|ccccccccccc|}
\hline Binder used & K/S & \multicolumn{2}{c}{ Rubbing } & \multicolumn{3}{c}{ Washing } & \multicolumn{5}{c|}{ Perspiration fastness } \\
& & & & \multicolumn{3}{c}{ Acidic } & \multicolumn{2}{c|}{ Alkaline } \\
Commercial & 3.8 & Dry & Wet & St. & Alt. & St. & Alt. & St. & Alt. \\
binder & & 3 & 3 & $4-5$ & 4 & $4-5$ & 4 & $4-5$ & 4 \\
Binder 1 & 5.4 & $\mathbf{3}$ & $\mathbf{3}$ & $4-5$ & 4 & $4-5$ & 4 & $4-5$ & 4 \\
Binder 2 & 7.1 & $3-4$ & $\mathbf{3}$ & $4-5$ & 4 & $4-5$ & 4 & $4-5$ & 4 \\
Binder 3 & 5.6 & $\mathbf{3}$ & $\mathbf{3}$ & $4-5$ & 4 & $4-5$ & 4 & $4-5$ & 4 \\
Binder 4 & 6.8 & $\mathbf{3}$ & $\mathbf{3}$ & $4-5$ & 4 & $4-5$ & 4 & $4-5$ & 4 \\
Binder 5 & $\mathbf{8}$ & $\mathbf{3}$ & $2-3$ & $4-5$ & 4 & $4-5$ & 4 & $4-5$ & 4 \\
Binder 6 & 8.8 & $3-4$ & $\mathbf{4}$ & $4-5$ & 4 & $4-5$ & 4 & $4-5$ & 4 \\
Binder 7 & 8.1 & $\mathbf{4}$ & $\mathbf{3}$ & $4-5$ & 4 & $4-5$ & 4 & $4-5$ & 4 \\
\hline
\end{tabular}

St. $=$ Staining $\quad$ Alt $=$ Alteration 
Tables 3 represent the color strength and overall fastness properties of screen printed and UV cured (for $3 \mathrm{~min}$.) cotton fabrics using pigment printing pastes containing $1 \%$ polyurethane acrylate binders (1-7), as well as $5 \%$ Bercolin Red B3E pig ment, as well as the commercial binder Ebecryl 2001 respectively. The results show that, the fastness properties of the printed samples depend slightly on the type of binder used as well as the type of the selected fabric. Binders 3, 4, 6 and 7 gave printed samples with much higher color strength results as compared to those obtained by binder 1, 2, 5 and the commercial binder.

Table 4 shows the roughness properties of screen printed cotton fabrics, using printing pastes containing ( $4 \%$ Bercolin Red B3E, $1 \%$ of the synthesized polyurethane acrylate binders (1-7), as well as the commercial binder Ebecryl 2001) and UV cured for $5 \mathrm{~min}$. at wave length $254 \mathrm{~nm}$. The results show that the roughness of printed fabrics depends on the type of binder used. Binders 3, 6 and7 gave high roughness results compared to commercial binder used.

Table 4. Roughness properties of screen printed UV cured cotton fabrics using prepared and commercial binders

\begin{tabular}{|cc|}
\hline Binder used & Printed Cotton \\
Commercial & 14.4 \\
Binder & 12.1 \\
Binder 1 & 14.4 \\
Binder 2 & 16 \\
Binder 3 & 12.7 \\
Binder 4 & 13.5 \\
Binder 5 & 15 \\
Binder 6 & 15.1 \\
Binder 7
\end{tabular}

Table 5 represent the color strength and overall fastness properties of screen printed cotton fabrics using pigment printing pastes containing $1 \%$ polyurethane acrylate binders (1-7), as well as 5\% Bercolin Red B3E pigment, and those obtained upon using the commercial binder Ebecryl 2001 and mic rowave cured (for $3 \mathrm{~min}$. ). The results show that, the washing and perspiration fastness properties of the printed samples are in depended on binder or fabric type. While in case of rubbing fastness properties it depends on the type of binder used as well as the selected fabric. It could be also noticed that the rubbing fastness results for printed samples, upon using all the aforementioned synthesized polyurethane acrylate binders through the use of microwave curing technique as compared to those obtained by the traditional thermal curing technique, some imp rovement is noticed with binders 2, 4, 5, 6 and 7 as compared to those for binder 1, 3 and the commercial binder especially in case of using these binders for printed polyester fabric, the rubbing fastness ranging fro m good to very good in case of using the binders 2 , 4, 5, 6, 7 and commercial binder and ranging from moderate to good in case of using binder 1,3. The washing and perspiration fastness ranged from very good to excellent for all binders. As mentioned before radiation in energy controlled by the electron vibrating in the molecules at the surface of a body. The amount of energy is that can be transformed depends on the absolute temperature of body and radiation properties of the surface.

However to date, microwave curing has only been studied by experimental methods.

Table 5. Overall fastness properties of pigment printed microwave cured cotton fabric using prepared and commercial binders

\begin{tabular}{|c|c|c|c|c|c|c|c|c|c|}
\hline \multirow[b]{3}{*}{ Binder used } & \multirow[b]{3}{*}{$\mathrm{K} / \mathrm{S}$} & \multirow{2}{*}{\multicolumn{2}{|c|}{ Rubbing }} & \multirow{2}{*}{\multicolumn{2}{|c|}{$\begin{array}{l}\text { Washing } \\
\text { fastness }\end{array}$}} & \multicolumn{4}{|c|}{ Perspiration fastness } \\
\hline & & & & & & \multicolumn{2}{|c|}{ Acidic } & \multicolumn{2}{|c|}{ Alkaline } \\
\hline & & Dry & Wet & St. & Alt. & St. & Alt. & St. & Alt. \\
\hline Commercial binder & 3.9 & 3 & 3 & $4-5$ & 4 & $4-5$ & 4 & $4-5$ & 4 \\
\hline Binder 1 & 7.2 & 3 & 3 & $4-5$ & 4 & $4-5$ & 4 & $4-5$ & 4 \\
\hline Binder 2 & 6.8 & 3 & 3 & $4-5$ & 4 & $4-5$ & 4 & $4-5$ & 4 \\
\hline Binder 3 & 7 & $2-3$ & $2-3$ & $4-5$ & 4 & $4-5$ & 4 & $4-5$ & 4 \\
\hline Binder 4 & 5.9 & $2-3$ & $2-3$ & $4-5$ & 4 & $4-5$ & 4 & $4-5$ & 4 \\
\hline Binder 5 & 5.5 & $3-4$ & 3 & $4-5$ & 4 & $4-5$ & 4 & $4-5$ & 4 \\
\hline Binder 6 & 6.8 & $2-3$ & 3 & $4-5$ & 4 & $4-5$ & 4 & $4-5$ & 4 \\
\hline Binder 7 & 9.3 & $2-3$ & $2-3$ & $4-5$ & 4 & $4-5$ & 4 & $4-5$ & 4 \\
\hline
\end{tabular}


Table 6 shows the roughness properties of screen printed cotton fabrics, using printing pastes containing (4\% Bercolin Red B3E, $1 \%$ of the synthesized polyurethane acrylate binders (1-7), as well as the commercial binder Ebecryl 2001) and microwave cured for $5 \mathrm{~min}$. at 500 watt.

The data show that the roughness for all these printed fabrics depends on the type of binder used. Binders 1, 2, 3, 4, 6 and7 gave higher roughness results compared to commercial binder used.

Table 6. Roughness properties of screen printed microwave cured cotton fabrics using prepared and commercial binders

\begin{tabular}{|cc|}
\hline Binder used & Printed Cotton \\
Commercial & \\
Binder & 8.99 \\
Binder 1 & 9,78 \\
Binder 2 & 13,5 \\
Binder 3 & 10.89 \\
Binder 4 & 9.1 \\
Binder 5 & 8 \\
Binder 6 & 9.11 \\
Binder 7 & 14.9 \\
\hline
\end{tabular}

\section{Conclusions}

FT-IR spectra of binders via UV curing show the disappearance of ast $\mathrm{C}=\mathrm{C}$ and $\delta$ : $=\mathrm{C}-\mathrm{H}$ absorption bands from the spectra chart of cured, which proofed the occurrence of cross linking reaction via terminal free acrylate double bond. Color strength of printed fabrics depends on binders' type and concentration as well as the fixation temperature. The K/S values at lower fixation temperatures on using the prepared binders in the printing paste are better than the K/S of fabric printed with paste including the commercial binder at the same condition ( saving energy). The fastness properties of the printed samples depend on the type of binder used. The washing and perspiration ranged from good to excellent for all printed samples. Slightly enhancement in K/S values of printed cotton fabric with increase the concentration of aliphatic polyurethane acrylate binders was noticed. Binder concentration of $1 \%$ produces cotton printed samples with higher color strength values within aromatic urethane acrylate binders than $4 \%$ of the same group. Increasing the UV-curing fixation time fro 3 to 5 and up to $10 \mathrm{~min}$. did not result in any significance increase in the color strength values of printed cotton fabric. The presence of $1 \%$ concentration of polyurethane acrylate binders (1-7) in the cotton pigment printing pastes, and either UV curried or microwave curing for $3 \mathrm{~min}$. could be considered as optimum conditions.

Improved rubbing fastness results for all the printed samples using the synthesized polyurethane acrylate binders in printed paste and UV cured are noticed as compared to those obtained by the traditional thermal curing technique. The washing and perspiration fastness results are comparable for the printed samples produced by the two techniques. Improved rubbing fastness results for all the printed samples using the synthesized polyurethane acrylate binders and micro wave curing are noticed as compared to those obtained by the traditional thermal curing technique. Rubbing fastness are in range from good to very good in case of using the binders 2, 4, 5, 6, 7 and commercial binder while it in rang from moderate to good in case of using binder 1,3 . The washing and perspiration fastness are in rang of very good to excellent for all samples printed with pasts including the prepared binders as well as the commercial one.

\section{REFERENCES}

[1] S. Li, H. Boyter and N. Stewart, "Ultraviolet (UV) Curing for Textile Color ation", AATCC Review, 44 (2004).

[2] R. Eisenlob, v. Giessen, "international dyer"180(3), 12-16 (1995).

[3] W. Schwindt, G. Faulhaber, "The Development of Pigment Printing Over The Last 50 Years", 166 rev.prog, coloration,14(1984).

[4] M. D. Teli and V. Y. Ramani, "American Dyestuff Reporter", 81, 32-7 (1992).

[5] S. Li, H. Boyter and Neil Stewart, "Ultraviolet (UV) Curing for Textile Coloration", AATCC Review 4(8), 44-9 (2004).

[6] J. G. Belton; "Microwave-accelerated dye fixation"; Int. Dyers \& Text. Printer, Vol. 43(5), 662 (1980).

[7] Mohamed M. El-Molla, Karima Haggag, Fatma N. El-Shall, N. O. Shaker " Part 1: Synthesis and Evaluation of Novel Nano Scale Powdered Polyurethane Acrylate Binders " Advances in Chemical Engineering and Science, 2, 212-227,(2012)

[8] B. D. Judd and G. Wyszecki, "Color in business", Science and Industry, 3rd Ed. (1975).

[9] AATCC Technical Manual, Method 8, (1989), 68, 23(1993).

[10] AATCC Technical Manual, Method 36, (1972), 68, 23 (1993).

[11] AATCC Technical Manual, Method 15, (1989), 68, 30 (1993).

[12] M. M. El-Molla, I. Abd El-Thalouth," Technological Evaluation Of Methacrylic Acid/Fenugreek Gum Grafted Products As Thickener In Textile Printing", polymer\& polymer composites, 7(7) (1999).

[13] C. Decher, "UV Irradiation Curing Chemistry", pigment\& resin technology, 30(5), 278-86 (2001).

[14] Z. Wicks, F. Jones and S. Pappas, "Organic Coatings Science and Technology", 2nd edition, John Wiley and Sons Inc., New York, P 508-15 (1999).

[15] V. R. Gowariker, N. V. Viswanathan and J. Sreedhar, “Polymer science”, 1st edition (1986). 
[16] J. P. Fouassier, "New developments in photoinitiators and photosensitizers for conventional and laser curing of multifunctional organic materials", Surface Coatings International, 252-8 (1994).

[17] S. Li, H. Boyter and N. Stewart, "Ultraviolet (UV) Curing for Textile Coloration", AATCC Review, 44 (2004).

[18] C. Decher," kinetic study and new application of uv radiation curing", Macromol. Rapid commun., 23(18) (2002).

[19] W. K. Walsh, W. Oraby, A. Makati and E. Bittencourt, Proc. AATCC Symposium, "Printing, Meeting the challenge of the'80’s." AATCC, Res. Triangle Park, N.C.27709 (1978).

[20] W. K. Walsha and W. Oraby " Radiation curing of pigment prints on textiles", Radiation Phy sics and Chemistry,14 Issues 3-6, 893-904 (1979).

[21] W. K. Walsh, W. Oraby, A. Makati and E. Bittencourt, "Water- Free, Low Energy Coloration Processes for Textile", First Semiannul Report to NSF. Grant APR 77-13895(1978).

[22] V. Shukla, M. Bajpai, D.K. Singh, M. Singh, R. Shukla, (2004) "Review of basic chemistry of UV-curing technology", Pigment \& Resin Technology, 33 5, 272 - 279 (2004).

[23] C. Decker, K. Zahouily, D. Decker, T. Nguyen and T. Viet, "Performance analysis of acylphosphineoxides in photoinitiated polymerization", Poly mer, 42, 7551-60 (2001).
[24] J. P. Fouassier, Editor, "Photoinitiation, photopolymerization, and photocuring: fundamentals and applications." Hanser / Gardner Publications, (1995).

[25] L. O. W. Abdoua, O. A. Hakeim, M. S. El-Din and M. S. El-Gammal, "Pigment Printing On Cotton and Polyester Fabrics With Electron Beam Irradiation Curable Formulation", journal of applied polymer science, 111, 1892-9 (2009).

[26] R. L. Shogren, and A. Biswas; "preparation of water-soluble and water-swellable starch acetate using $\mathrm{j}$ microwave Heating", Carbohy drate Polymers, 46, 16-21 (2006).

[27] K. Haggag, H. L. Hanna, B. M. Yousef and N. S. El-Shimy; "Dyeing Polyester with Microwave: Heating Using Disperse Dyestuffs"; Amer. Dy est. Rep., 84(5), 22 (1995).

[28] G. Horeise, S. Pichler, A. Stadler, W. Gossler, and C.O. Kappe, "Microwave-Assisted Organic Synthesis-Back To The Roots" ,Fifth International Ekectronic Conference On Organic Chemistry(ECSOC-5), 1-30 September (2001).

[29] K. Mehnet, H. Peter, Color Technol., 300, 118 (2002).

[30] A. W. M. El-Naggar, Applied Surface Science, 241, 420-430 (2005). 